\title{
LACK OF HINOKITIOL (BETA-THUJAPLICIN) CARCINOGENICITY IN F344/DuCrj RATS
}

\author{
Norio IMAI ${ }^{1,2}$, Yuko DOI $^{1,2}$, Kyoko NABAE $^{1,2}$, Seiko TAMANO ${ }^{1}$, Akihiro HAGIWARA ${ }^{1}$, \\ Mayumi KAWABE ${ }^{1}$, Toshio ICHIHARA ${ }^{1}$, Kumiko OGAWA $^{2}$ and Tomoyuki SHIRAI ${ }^{2}$ \\ ${ }^{1}$ DIMS Institute of Medical Science, Inc., \\ 64 Goura, Nishiazai, Azai-cho, Ichinomiya 491-0113, Japan \\ ${ }^{2}$ Department of Experimental Pathology and Tumor Biology, \\ Nagoya City University Graduate School of Medical Sciences, \\ 1 Kawasumi, Mizuho-cho, Mizuho-ku, Nagoya 467-8601, Japan
}

(Received June 9, 2006; Accepted July 31, 2006)

\begin{abstract}
Chronic toxicity and carcinogenicity of hinokitiol (beta-thujaplicin), used as an antibiotic and fungicidal agent of a food additive, was examined in both sexes of F344/DuCrj (F344) rats. In this chronic toxicity study, groups of 10 rats of each sex were given a diet containing hinokitiol at doses of $0,0.005,0.015$ and $0.05 \%$ for 52 weeks. No treatment-related adverse effects were noted in the survival rate, general condition, body weights, food consumption, urinalysis, hematology and clinical chemistry. Slight but significant elevation of spleen and liver weights was noted in both sexes given $0.05 \%$ hinokitiol, along with an increase in hemosiderin deposits in male spleens, related to chelator binding of iron, together with slight centrilobular hypertrophy of male hepatocytes. However, these alterations were negligible and not toxicologically significant.

In the carcinogenicity study, groups of 50 female and 50 male rats were given a diet containing hinokitiol at doses of $0,0.005,0.015$ and $0.05 \%$ (excluding $0.005 \%$ in females). No treatment-related changes in survival rate, general condition, body weight, food consumption, hematology and organ weights were noted. Detailed histopathological examination revealed no treatment-related increase in the incidences of any neoplastic lesions. The results demonstrate that hinokitiol is not carcinogenic in F344 rats of either sex.
\end{abstract}

KEY WORDS: Hinokitiol, Beta-Thujaplicin, Food additive, Carcinogenicity, F344 rats

\section{INTRODUCTION}

Hinokitiol (beta-thujaplicin), extracted from Chamaecyparis taiwanensis, growing in Japan and Taiwan and belonging to Cupressaceae, exerts antibacterial and antifungal activities, and has found an application as a fungicide in food and cosmetics and as a tick repellent. Hinokitiol features a unique tropolone structure which is specific for Cupressaceae. The acute oral $\mathrm{LD}_{50}$ of hinokitiol is $504 \mathrm{mg} / \mathrm{kg}$ bw for male and 469 $\mathrm{mg} / \mathrm{kg}$ bw for female mice (Shimizu et al., 1993). In a chronic toxicity study using mice, an increase in Sudan-positive pigments was apparent in the adrenal cortex (Nakano, 1959). In an in vitro isolated rat hepa- tocytes system, hinokitiol-induced cytotoxicity was found in association with an acute ATP depletion via mitochondrial dysfunction with induction of cytotoxicity altered by EDTA or divalent cations (Nakagawa and Tayama, 1998). Hinokitiol is a potent iron-chelating agent (Tanaka et al., 1995), inducing reversible differentiation in embryonal carcinoma cells (Tanaka et al., 1997) and apoptosis through activation of caspase-3 (Ido et al., 1999; Tanaka et al., 1999). In a teratogenicity study using ICR mice, a high dose level of hinokitiol (560 mg/kg or more) induced various types of malformations in fetuses (Ogata et al., 1999), with an $\mathrm{ED}_{1}$ of $190 \mathrm{mg} / \mathrm{kg}$. However, no developmental toxicity was apparent when pregnant rats were given up to $135 \mathrm{mg} /$

Correspondence: Seiko Tamano (E-mail: tamano@dims.co.jp) 
$\mathrm{kg}$ of hinokitiol (Ema et al., 2004). Very weak genotoxic activity of hinokitiol was found in spore recassay with a non-S9 mixture (Ueno and Ishizuka, 1992) but toxicological information is otherwise limited.

The present study was conducted to assess the possible chronic toxicity and carcinogenicity of hinokitiol given in the diet for 52 and 104 weeks to F344 rats of both sexes.

\section{MATERIALS AND METHODS}

\section{Test chemical and diet}

The Hinokitiol sample (Lot No. 12070001) was a white or pale yellow crystalline solid, its chemical formula being illustrated in Fig.1. Hinokitiol was obtained from Osaka Organic Chemical Industry, Ltd. (Kashiwara, Japan) mediated through Seiwa Technics Co., Ltd. (Tokyo, Japan) and incorporated at the required levels into irradiated $(6.0 \mathrm{kGy})$ powder diet MF (Oriental Yeast Co., Ltd., Tokyo, Japan). Diet sample analyses of hinokitiol (Seiwa Technics Co., Ltd.) demonstrated 92.2 to $106.7 \%$ of the expected levels. The diets were prepared every 4 weeks and kept in the dark at $4^{\circ} \mathrm{C}$ until use since hinokitiol was confirmed to be stable for over 4 weeks in the refrigerator. Dosage levels of hinokitiol were selected based on a prelimi-

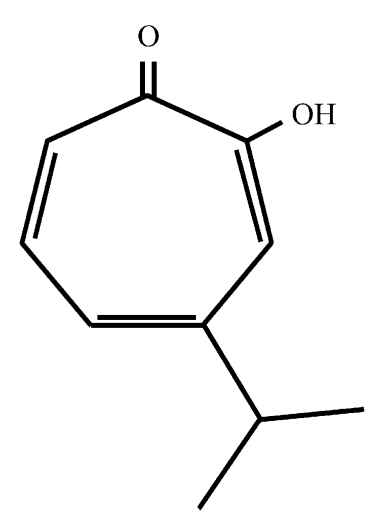

CAS No. : 499-44-5

Molecular name : 2,4,6-Cycloheptartrien-1-one,

$$
\text { 2-hydroxy-4-(1-methyl) }
$$

nary 13 -week oral toxicity study using both sexes of F344/DuCrj rats administered a diet containing the compound at doses of $0,0.05,0.1$ and $0.2 \%$. All male rats given $0.1 \%$ hinokitiol died from dyspnea with large amounts of pleural fluid from experimental weeks 6 to 7 . Three out of ten male rats given $0.2 \%$ hinokitiol also died with similar symptoms at experimental week 13. However, no deaths were observed in the females. Slight to moderate myocarditis, associated with dilatation of ventricles and large amounts of pleural fluid, was observed in male rats given diets containing $0.05,0.1$ and $0.2 \%$ of hinokitiol. This appeared to be linked to slight hepatocellular necrosis and changes in clinical biochemistry parameters in male rats. However, no such findings were ever encountered in females.

In an additional 13-week oral toxicity study of hinokitiol, deaths and moderate myocarditis associated with pleural fluid and slight hepatocellular vacuolar degeneration were confirmed in male F344 rats receiving $0.1 \%$ hinokitiol without any dose-dependent toxic response, similar to the results obtained in the previous 13-week oral toxicity study mentioned above, although death for male rats receiving $0.1 \%$ hinokitiol was observed in one rat during experimental week 13 . From these results, the dietary level of $0.05 \%$ hinokitiol was judged as the maximum tolerable dosage that would be suitable for the highest dose level in the present long-term experiment.

\section{Animals and maintenance}

F344/DuCrj (F344) rats, 4 weeks old, were purchased from Charles River Japan, Inc., (Atsugi, Japan) and allowed a 7-day quarantine and acclimation period, during which body weight and health conditions were monitored. After confirmation of normal health status, they were used for the experiments at the age of 5 weeks. The animals were housed two or three to polypropylene cages $(26.0 \mathrm{~cm}$ wide $\times 41.2$ long $\times 19.5$ high) with hardwood Beta Chips (Northeastern Product Co., Warrensburg, NY) for bedding. The room temperature and relative humidity were controlled at $19.5 \sim 25.5^{\circ} \mathrm{C}$ and $49.5 \sim 64 \%$, respectively, and the room air was changed more than 15 times per hour. Fluorescent light provided a 12-hr light/dark cycle. Irradiated MF powder diet and tap water were supplied ad libutum. The animals were weighed and randomly assigned to dose groups on the day before starting the study.

Fig. 1. Chemical structure of hinokitiol. 
Chronic toxicity/carcinogenicity of hinokitiol.

\section{Experimental procedure}

\section{One-year chronic toxicity}

Groups of 10 female and 10 male rats were given diets containing $0,0.005,0.015$ and $0.05 \%$ hinokitiol for 52 weeks. All animals were examined once a day for general health and signs of toxicity. Individual body weights were measured weekly for the first 14 weeks and once every 2 weeks thereafter. Food intake was measured over a 2-day period before each weighing. Urinalysis of samples collected over a 4-hr period (from 9:00 AM to 1:00 PM) was conducted for all surviving animals during week 52; semiquantitative estimation (Multistix, Miles-Sankyo Co., Ltd., Tokyo, Japan) of protein glucose, ketones, bilirubin, occult blood and urobilinogen was included. Specific gravity values were measured using a reflectance meter (Atago Co., Ltd., Tokyo, Japan). The levels of electrolytes (sodium, potassium and chloride) were determined using a Hitachi Biochemical-Automatic Analyzer 7070 (Hitachi Co., Ltd., Tokyo, Japan). Urine volumes were measured by weighing. Urine was inspected macroscopically and sediments assessed by microscopy of specimens stained with Labostin (Muto Chemicals Co., Ltd., Kyoto, Japan). In addition, fresh urine samples were obtained, and urinary $\mathrm{pH}$ values measured using a pH meter (Horiba Ltd., Kyoto, Japan).

At the end of week 52, animals were fasted overnight before euthanasia under ether anesthesia. Whole blood samples were collected via the abdominal aorta from all surviving rats and hematological estimations were performed (Sysmex F820; Sysmex Co., Ltd., Kobe, Japan) for the erythrocyte count (RBC), total leukocyte count (WBC), hemoglobin concentration (HB), hematocrit (HT), platelet count (PLT), mean corpuscular hemoglobin $(\mathrm{MCH})$, mean corpuscular volume (MCV) and mean corpuscular hemoglobin concentration (MCHC). Differential counts of leukocytes and reticulocytes (Retic) were made by microscopy of Wright and Brecher stained specimens, respectively.

Blood biochemistry determinations were performed with a Hitachi Biochemical-Automatic Analyzer 7070 (Hitachi Co., Ltd., Tokyo, Japan). Parameters included asparaginic acid aminotransferase (AST), alanine aminotransferase (ALT), alkaline phosphatase (ALP), total bilirubin (T-BIL), blood urea nitrogen (BUN), creatinine (CRE), glucose (GLU), total cholesterol (T-CHO), phospholipid (PL), trigryceride (TG), total protein (TP), albumin (ALB), the albumin/globulin ratio $(\mathrm{A} / \mathrm{G})$, inorganic phosphorus (IP), calcium $(\mathrm{Ca})$, magnesium $(\mathrm{Mg})$, sodium $(\mathrm{Na})$, potassium $(\mathrm{K})$ and chlorine $(\mathrm{Cl})$.
Gross examination was made at autopsy. The following organs of each rat were weighed and the organto-body weight ratios were determined: brain, pituitary, heart, lungs (including bronchi), liver, spleen, kidneys, adrenals, testes, prostate (ventral lobe), seminal vesicles, ovaries (including oviducts), uterus, salivary glands, thymus and thyroids (including parathyroids). Samples of these organs and of the lymph nodes, bone marrow, trachea, nasal cavity, tongue, esophagus, stomach, duodenum, jejunum, ileum, cecum, colon, rectum, pancreas, urinary bladder, epididymides, mammary gland, vagina, femur, sternum, skin, skeletal muscle, aorta, eyes, Harderian glands, Zymbal's glands, spinal cord, sciatic nerve and any other tissues of abnormal appearance were fixed in $10 \%$ buffered formalin. Testes were fixed in glutaraldehyde formalin acetic acid (GFA). A full histopathological examination was performed on hematoxylineosin-stained tissue sections of the organs and tissues listed above. In order to identify hemosiderin in the spleen, five representative paraffin sections from each group were stained with Berlin blue and colored area measured using a video image processor (IPAPWIN)(Sumika Technos. Co., Osaka Japan), and evaluated quantitatively.

\section{Two-year carcinogenicity}

Groups of 50 female and 50 male rats were given diets containing 0, 0.005 (males only, since a dietary level of $0.1 \%$ was lethal for males, and would not be considered to be tolerated for two-year treatment for females, but females tolerated quite well a dietary level of $0.05 \%$ in the preliminary 13 -week oral toxicity study) with 0.015 and $0.05 \%$ hinokitiol for 104 weeks.

All animals were examined once a day for general health and signs of toxicity. Individual body weights were measured weekly for the first 14 weeks and once every 4 weeks thereafter. Food intake was measured over a 2-day period before each weighing.

After 104 weeks, all surviving rats were deprived of food, but not water, overnight and then killed under ether anesthesia by exsanguination from the abdominal aorta. Hematological determinations of the blood, including an erythrocyte count, leukocyte count, measurements of the hemoglobin concentration, hematocrit value and a platelet count were performed (Sysmex F820; Sysmex Co., Ltd., Kobe, Japan) on 10 rats each group. Blood smears for all survived animals were used to check for leukemia. In addition, gross pathological and histopathological examinations were performed as well for one-year chronic toxicity. 
N. IMAI et al.

All experimental procedures were performed in accordance with the in-house guidelines for the Care and Use of Laboratory Animals at DIMS Institute of Medical Science, Inc.

\section{Statistical analysis}

Data on cumulative mortality were analyzed by means of the Kaplan-Meier method. The significance of intergroup differences in body weight was assessed using Dunnett's multiple comparison test (Dunnett, 1955). For incidence of histopathological lesions, the significance of differences observed between the controls and treated groups was evaluated with the Fisher's exact test (Fisher, 1955) or Mann-Whitney test (Gad and Weil, 1989). The levels of significance were set at $\mathrm{p}<0.05$ and 0.01 .

\section{RESULTS}

\section{One-year chronic toxicity}

No treatment-related alteration in physical appearance or general behavior was observed in any of the rats throughout the study. One male rat from $0.005 \%$ group died from a malignant pheochromocytoma in experimental week 40.

No significant differences in body weight changes were observed in any hinokitiol-treated groups of both sexes as compared with controls. Food consumption in controls and treated animals showed no clear-group differences. The average hinokitiol intakes by females and males, respectively, were 2.9 and $2.4 \mathrm{mg} / \mathrm{kg}$ b.w./day in the $0.005 \%$ group, 8.5 and $7.2 \mathrm{mg} / \mathrm{kg}$ b.w./day in the $0.015 \%$ group, and 29.1 and $24.6 \mathrm{mg} / \mathrm{kg}$ b.w./day in the $0.05 \%$ group, showing a dose-dependent proportional increase.

On urinalysis, slightly decreased specific gravity was noted in the $0.05 \%$ male group (data not shown).

Hematology data are summarized in Table 1. No hinokitiol treatment-related adverse effects were apparent. Although the WBC counts in groups of the $0.05 \%$ female, and the 0.015 and $0.05 \%$ males were significantly higher than those of controls, these changes were not considered to be toxicologically significant because of the lack of elevation of any neutro-

Table 1. Hematological data in F344 rats treated with Hinokitiol in chronic study.

\begin{tabular}{|c|c|c|c|c|c|c|}
\hline \multirow{2}{*}{ Parameters } & \multicolumn{6}{|c|}{ Hinokitiol in diet (\%) } \\
\hline & & 0 & 0.005 & 0.015 & & .05 \\
\hline \multicolumn{7}{|l|}{ Females } \\
\hline $\mathrm{RBC}\left(\times 10^{4} / \mu \mathrm{l}\right)$ & 810.5 & \pm 25.7 & $813.2 \pm 22.0$ & $818.7 \pm 28.7$ & 796.5 & \pm 37.3 \\
\hline $\mathrm{WBC}\left(\times 10^{2} / \mu \mathrm{l}\right)$ & 21.5 & \pm 2.8 & $23.0 \pm 3.0$ & $25.0 \pm 5.7$ & 26.5 & $\pm 3.7 *$ \\
\hline $\mathrm{HB}(\mathrm{g} / \mathrm{dl})$ & $14.8=$ & \pm 0.4 & $14.8 \pm 0.5$ & $15.0 \pm 0.4$ & 15.1 & \pm 0.7 \\
\hline HT $(\%)$ & $43.7=$ & \pm 2.5 & $43.5 \pm 2.8$ & $43.7 \pm 2.6$ & 43.3 & \pm 2.7 \\
\hline MCV (fl) & 54.0 & \pm 3.3 & $53.5 \pm 3.5$ & $53.4 \pm 2.9$ & 54.3 & \pm 2.8 \\
\hline $\mathrm{MCH}(\mathrm{pg})$ & 18.2 & \pm 0.3 & $18.2 \pm 0.6$ & $18.4 \pm 0.2$ & 19.0 & $\pm 0.9 * *$ \\
\hline $\mathrm{MCHC}(\%)$ & 33.9 & \pm 1.7 & $34.1 \pm 2.0$ & $34.5 \pm 1.8$ & 35.0 & \pm 2.8 \\
\hline Platelet $\left(\times 10^{4} / \mu \mathrm{l}\right)$ & 56.9 & \pm 3.2 & $58.1 \pm 6.0$ & $57.6 \pm 3.0$ & 57.5 & \pm 4.3 \\
\hline Reticulocyte count (\%) & 1.38 & \pm 0.64 & $1.12 \pm 0.39$ & $1.13 \pm 0.26$ & 1.03 & \pm 0.22 \\
\hline \multicolumn{7}{|l|}{ Males } \\
\hline $\mathrm{RBC}\left(\times 10^{4} / \mu \mathrm{l}\right)$ & 889.3 & \pm 36.2 & $888.7 \pm 24.9$ & $906.3 \pm 19.4$ & 883.7 & \pm 23.2 \\
\hline WBC $\left(\times 10^{2} / \mu 1\right)$ & 27.4 & \pm 6.4 & $31.6 \pm 4.9$ & $34.6 \pm 8.2 *$ & $35.5=$ & $\pm 6.2 *$ \\
\hline $\mathrm{HB}(\mathrm{g} / \mathrm{dl})$ & $14.7=$ & \pm 0.3 & $14.8 \pm 0.3$ & $15.0 \pm 0.2 *$ & 15.1 & $\pm 0.3 * *$ \\
\hline $\mathrm{HT}(\%)$ & 42.3 & \pm 2.2 & $42.8 \pm 2.0$ & $44.4 \pm 2.0^{*}$ & $43.8=$ & \pm 1.5 \\
\hline $\operatorname{MCV}(\mathrm{fl})$ & $47.6=$ & \pm 1.7 & $48.2 \pm 1.9$ & $48.9 \pm 2.1$ & $49.6=$ & $\pm 2.1^{*}$ \\
\hline MCH (pg) & 16.5 & \pm 0.7 & $16.7 \pm 0.6$ & $16.5 \pm 0.3$ & 17.1 & $\pm 0.4^{*}$ \\
\hline $\mathrm{MCHC}(\%)$ & $34.7=$ & \pm 1.7 & $34.6 \pm 2.1$ & $33.8 \pm 1.3$ & $34.5=$ & \pm 1.1 \\
\hline Platelet $\left(\times 10^{4} / \mu \mathrm{l}\right)$ & $61.4=$ & \pm 5.2 & $62.7 \pm 4.9$ & $60.0 \pm 4.8$ & $60.6=$ & \pm 4.2 \\
\hline Reticulocyte count (\%) & 1.05 & \pm 0.31 & $0.90 \pm 0.26$ & $0.92 \pm 0.19$ & 0.97 & \pm 0.29 \\
\hline
\end{tabular}

Values are Mean \pm SD values.

Data for differential counts of leukocytes were excluded from this table, since statistically significant changes were not found in any group.

$*$, ** : Significantly different from control group at $\mathrm{p}<0.05, \mathrm{p}<0.01$, respectively. 
Chronic toxicity/carcinogenicity of hinokitiol.

phil population. The significantly elevated hemoglobin concentrations noted in groups of the 0.015 and $0.05 \%$ males were considered to be incidental because the RBC counts were not different from those of controls.

Blood biochemistry data are summarized in Table 2. Significant elevation of AST and ALT was found in the $0.015 \%$ females and of BUN in the $0.05 \%$ males. Significant lowering of $\mathrm{A} / \mathrm{G}$ was found in the 0.005 and $0.05 \%$ females. However, these changes were not considered to be biologically significant because of no dose-related alterations.

Final body weight and relative organ weight data are given in Table 3. Significantly elevated relative liver, kidneys and spleen were noted in the $0.05 \%$ female group, along with significantly elevated relative lung, liver, spleen and testes weight in the $0.05 \%$ males.

Histopathological findings are summarized in Table 4. Myocarditis observed in two preliminary 13week oral toxicity studies was not evident in any male groups given hinokitiol, only being found in association with slight mononuclear cell infiltration in male control rats. Slight but significant increase in hemosiderin deposits was apparent in the spleens of male rats receiving $0.05 \%$ hinokitiol, increased blue areas stained by Berlin blue being evident (Table 5). Slight centrilobular hypertrophy of hepatocytes was observed in the same group. In addition, the incidence of hyper-

Table 2. Blood biochemistry data in F344 rats treated with Hinokitiol in chronic study.

\begin{tabular}{|c|c|c|c|c|c|c|c|c|}
\hline \multirow{2}{*}{ Parameters } & \multicolumn{8}{|c|}{ Hinokitiol in diet $(\%)$} \\
\hline & \multicolumn{2}{|r|}{0} & \multicolumn{2}{|c|}{0.005} & \multicolumn{2}{|c|}{0.015} & \multicolumn{2}{|c|}{0.05} \\
\hline \multicolumn{9}{|l|}{ Females } \\
\hline AST (U/l) & 67 & \pm 9 & 79 & \pm 32 & 78 & $\pm 14^{*}$ & 70 & \pm 7 \\
\hline ALT (U/l) & 37.6 & \pm 5.3 & 43.3 & \pm 19.6 & 43.4 & $\pm 5.1^{*}$ & 41.3 & \pm 6.4 \\
\hline ALP (IU/l) & 135 & \pm 16 & 135 & \pm 39 & 131 & \pm 25 & 139 & \pm 21 \\
\hline T-BIL (mg/dl) & 0.048 & \pm 0.014 & 0.050 & \pm 0.023 & 0.048 & \pm 0.010 & 0.047 & \pm 0.008 \\
\hline BUN (mg/dl) & 21.0 & \pm 2.9 & 21.7 & \pm 1.2 & 22.8 & \pm 1.9 & 21.6 & \pm 2.3 \\
\hline CRE (mg/dl) & 0.51 & \pm 0.03 & 0.52 & \pm 0.04 & 0.52 & \pm 0.06 & 0.48 & \pm 0.04 \\
\hline GLU (mg/dl) & 114 & \pm 15 & 116 & \pm 14 & 114 & \pm 14 & 121 & \pm 7 \\
\hline T-CHO (mg/dl) & 115 & \pm 11 & 115 & \pm 18 & 121 & \pm 8 & 111 & \pm 10 \\
\hline PL (mg/dl) & 226 & \pm 22 & 222 & \pm 33 & 232 & \pm 15 & 217 & \pm 22 \\
\hline $\mathrm{TG}(\mathrm{mg} / \mathrm{dl})$ & 81 & \pm 29 & 83 & \pm 33 & 72 & \pm 22 & 84 & \pm 27 \\
\hline $\mathrm{TP}(\mathrm{g} / \mathrm{dl})$ & 6.34 & \pm 0.31 & 6.34 & \pm 0.36 & 6.44 & \pm 0.22 & 6.34 & \pm 0.34 \\
\hline $\operatorname{ALB}(\mathrm{g} / \mathrm{dl})$ & 2.90 & \pm 0.16 & 2.82 & \pm 0.21 & 2.93 & \pm 0.11 & 2.83 & \pm 0.19 \\
\hline $\mathrm{A} / \mathrm{G}$ & 0.84 & \pm 0.04 & 0.80 & $\pm 0.04 *$ & 0.84 & \pm 0.04 & 0.81 & $\pm 0.04^{*}$ \\
\hline \multicolumn{9}{|l|}{ Males } \\
\hline AST (U/l) & 113 & \pm 30 & 127 & \pm 34 & 106 & \pm 27 & 132 & \pm 30 \\
\hline ALT (U/l) & 68.0 & \pm 20.6 & 70.4 & \pm 18.8 & 60.3 & \pm 14.6 & 79.3 & \pm 19.0 \\
\hline ALP (IU/l) & 236 & \pm 60 & 239 & \pm 51 & 219 & \pm 48 & 211 & \pm 29 \\
\hline T-BIL (mg/dl) & 0.044 & \pm 0.015 & 0.048 & \pm 0.012 & 0.040 & \pm 0.008 & 0.052 & \pm 0.012 \\
\hline BUN (mg/dl) & 18.3 & \pm 1.8 & 19.5 & \pm 1.8 & 17.9 & \pm 2.3 & 20.3 & $\pm 1.9^{*}$ \\
\hline CRE (mg/dl) & 0.45 & \pm 0.07 & 0.48 & \pm 0.07 & 0.45 & \pm 0.05 & 0.47 & \pm 0.05 \\
\hline GLU (mg/dl) & 124 & \pm 21 & 128 & \pm 12 & 120 & \pm 20 & 120 & \pm 13 \\
\hline T-CHO (mg/dl) & 79 & \pm 16 & 78 & \pm 12 & 73 & \pm 13 & 82 & \pm 9 \\
\hline PL (mg/dl) & 128 & \pm 23 & 128 & \pm 20 & 121 & \pm 22 & 130 & \pm 11 \\
\hline TG (mg/dl) & 76 & \pm 17 & 80 & \pm 20 & 84 & \pm 30 & 98 & \pm 26 \\
\hline TP (g/dl) & 5.91 & \pm 0.62 & 6.16 & \pm 0.55 & 5.70 & \pm 0.88 & 6.25 & \pm 0.31 \\
\hline $\operatorname{ALB}(\mathrm{g} / \mathrm{dl})$ & 2.44 & \pm 0.28 & 2.54 & \pm 0.22 & 2.39 & \pm 0.37 & 2.57 & \pm 0.14 \\
\hline $\mathrm{A} / \mathrm{G}$ & 0.70 & \pm 0.02 & 0.71 & \pm 0.03 & 0.72 & \pm 0.03 & 0.70 & \pm 0.02 \\
\hline
\end{tabular}

Values are Mean \pm SD values.

Data for IP, $\mathrm{Ca}, \mathrm{Mg}, \mathrm{Na}, \mathrm{K}$ and $\mathrm{Cl}$ were excluded from this table, since no statistically significant changes were found.

$*, * *$ : Significantly different from control group at $\mathrm{p}<0.05, \mathrm{p}<0.01$, respectively. 
N. IMAI et al.

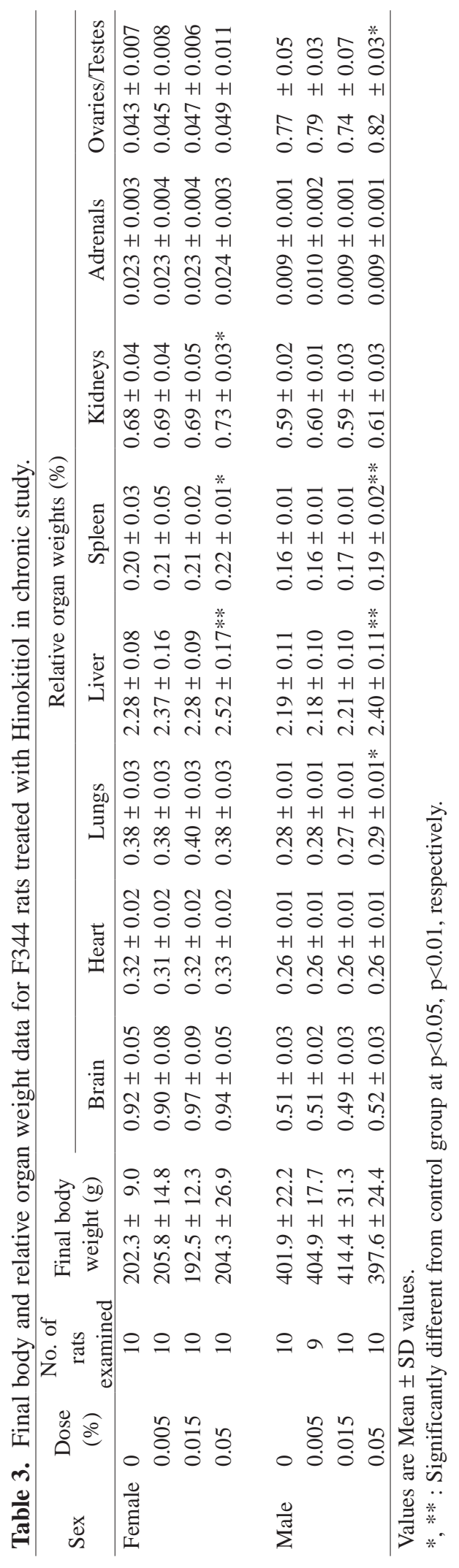


Chronic toxicity/carcinogenicity of hinokitiol.

Table 4. Histopathological findings in F344 rats treated with Hinokitiol in chronic study.

\begin{tabular}{|c|c|c|c|c|c|c|c|c|}
\hline \multirow{3}{*}{$\begin{array}{l}\text { Site and findings } \\
\text { Dietary level }(\%)---\end{array}$} & \multicolumn{8}{|c|}{ No. of rats with tumors } \\
\hline & \multicolumn{4}{|c|}{ Female } & \multicolumn{4}{|c|}{ Male } \\
\hline & 0 & 0.005 & 0.015 & 0.05 & 0 & 0.005 & 0.015 & 0.05 \\
\hline Heart & $(10)$ & $(10)$ & $(10)$ & $(10)$ & (10) & $(10)$ & $(10)$ & $(10)$ \\
\hline Cellular infiltration, mononuclear cell (1) & 0 & 0 & 0 & 0 & 3 & 3 & 7 & 6 \\
\hline Myocardial fibrosis (1) & 0 & 0 & 0 & 0 & 0 & 1 & 1 & 0 \\
\hline Spleen & $(10)$ & (10) & $(10)$ & $(10)$ & $(10)$ & $(10)$ & $(10)$ & $(10)$ \\
\hline Deposit, hemosiderin (1) & 0 & 0 & 0 & 0 & 0 & 0 & 0 & $10 * *$ \\
\hline Extramedullary hematopoiesis (1) & 1 & 1 & 0 & 1 & 0 & 0 & 0 & 0 \\
\hline Follicular hyperplasia & 0 & 1 & 0 & 0 & 0 & 0 & 0 & 0 \\
\hline Bone marrow & $(10)$ & (10) & (10) & (10) & (10) & $(10)$ & (10) & $(10)$ \\
\hline Hematopoiesis (1) & 0 & 0 & 0 & 1 & 0 & 0 & 0 & 0 \\
\hline Granulomatous inflammation (1) & 1 & 0 & 2 & 0 & 0 & 0 & 0 & 0 \\
\hline (2) & 0 & 1 & 0 & 0 & 0 & 0 & 0 & 0 \\
\hline Granuloma (1) & 0 & 0 & 1 & 0 & 0 & 0 & 0 & 0 \\
\hline Pituitary & $(10)$ & (10) & $(10)$ & $(10)$ & $(10)$ & (10) & (10) & $(10)$ \\
\hline Cyst (1) & 3 & 2 & 0 & 3 & 0 & 0 & 0 & 0 \\
\hline Hyperplasia, pars distalis & 0 & 2 & 2 & 0 & 0 & 1 & 1 & 2 \\
\hline Adenoma, pars distalis & 0 & 2 & 1 & 0 & 0 & 0 & 1 & 0 \\
\hline Thyroids & $(10)$ & (10) & (10) & $(10)$ & (10) & $(10)$ & (10) & $(10)$ \\
\hline Cyst (1) & 1 & 0 & 0 & 0 & 0 & 0 & 0 & 0 \\
\hline C-cell hyperplasia & 0 & 0 & 0 & 0 & 0 & 0 & 2 & 0 \\
\hline $\mathrm{C}$-cell adenoma & 0 & 0 & 0 & 0 & 0 & 0 & 1 & 0 \\
\hline Adrenals & $(10)$ & (10) & (10) & $(10)$ & $(10)$ & $(10)$ & (10) & $(10)$ \\
\hline Fatty metamorphosis (1) & 0 & 0 & 0 & 0 & 1 & 0 & 0 & 0 \\
\hline Medullary hyperplasia & 0 & 1 & 0 & 0 & 0 & 0 & 0 & 0 \\
\hline Malignant pheochromocytoma & 0 & 0 & 0 & 0 & 0 & 1 & 0 & 0 \\
\hline Lungs & $(10)$ & (10) & $(10)$ & $(10)$ & $(10)$ & $(10)$ & (10) & $(10)$ \\
\hline Edema (1) & 0 & 0 & 0 & 1 & 0 & 0 & 0 & 0 \\
\hline Hyperplasia & 0 & 1 & 0 & 1 & 2 & 0 & 1 & 0 \\
\hline Adenoma & 1 & 0 & 0 & 0 & 0 & 1 & 0 & 0 \\
\hline Pancreas & $(10)$ & $(10)$ & (10) & $(10)$ & $(10)$ & $(10)$ & (10) & $(10)$ \\
\hline Acinar cell atrophy (1) & 1 & 0 & 1 & 0 & 1 & 0 & 2 & 2 \\
\hline Cellular infiltration, lymphocyte (1) & 0 & 0 & 0 & 0 & 0 & 1 & 0 & 0 \\
\hline Liver & $(10)$ & (10) & (10) & $(10)$ & $(10)$ & $(10)$ & (10) & $(10)$ \\
\hline Cellular infiltration, lymphocyte (1) & 0 & 1 & 1 & 0 & 0 & 0 & 0 & 0 \\
\hline Granulomatous inflammation (2) & 0 & 1 & 0 & 0 & 0 & 0 & 0 & 0 \\
\hline Granuloma (1) & 1 & 1 & 2 & 0 & 1 & 0 & 0 & 1 \\
\hline Centrilobular necrosis (1) & 0 & 0 & 0 & 0 & 0 & 1 & 0 & 0 \\
\hline Hypertrophy, centrilobular (1) & 0 & 0 & 0 & 0 & 0 & 0 & 0 & $4 *$ \\
\hline Foci of cellular alterations & 8 & 8 & 6 & 4 & 4 & 1 & 1 & 2 \\
\hline Kidneys & $(10)$ & $(10)$ & (10) & $(10)$ & $(10)$ & $(10)$ & (10) & $(10)$ \\
\hline Mineralization, cortico-medullary junction (1) & 7 & 8 & 9 & 7 & 0 & 0 & 0 & 0 \\
\hline Infarction (1) & 0 & 1 & 0 & 0 & 0 & 0 & 0 & 0 \\
\hline Cellular infiltration, lymphocyte (1) & 0 & 0 & 0 & 0 & 0 & 1 & 1 & 1 \\
\hline Proteinaceous cast (1) & 0 & 0 & 0 & 0 & 1 & 1 & 0 & 0 \\
\hline Regeneration of tubular epithelium (1) & 0 & 0 & 0 & 1 & 1 & 1 & 2 & 2 \\
\hline Urinary bladder & $(10)$ & (10) & $(10)$ & $(10)$ & $(10)$ & $(10)$ & (10) & $(10)$ \\
\hline Cellular infiltration, lymphocyte (1) & 0 & 0 & 1 & 0 & 0 & 0 & 0 & 0 \\
\hline Papillomatous hyperplasia & 0 & 1 & 0 & 0 & 0 & 0 & 0 & 0 \\
\hline Papilloma & 0 & 1 & 0 & 0 & 0 & 0 & 0 & 0 \\
\hline
\end{tabular}

Grade : (1) slight (2) moderate.

Numbers of rats examined are indicated in parentheses.

$*$, ** : Significantly different from control group at $\mathrm{p}<0.05, \mathrm{p}<0.01$, respectively. 
N. IMAI et al.

Table 4. Continued.

\begin{tabular}{|c|c|c|c|c|c|c|c|c|}
\hline \multirow{3}{*}{$\begin{array}{l}\text { Site and findings } \\
\text { Dietary level }(\%)---\end{array}$} & \multicolumn{8}{|c|}{ No. of rats with tumors } \\
\hline & \multicolumn{4}{|c|}{ Female } & \multicolumn{4}{|c|}{ Male } \\
\hline & 0 & 0.005 & 0.015 & 0.05 & 0 & 0.005 & 0.015 & 0.05 \\
\hline Testes & - & - & - & - & (10) & $(10)$ & $(10)$ & $(10)$ \\
\hline Atrophy (1) & - & - & - & - & 0 & 1 & 1 & 1 \\
\hline (2) & - & - & - & - & 1 & 0 & 1 & 0 \\
\hline (3) & - & - & - & - & 1 & 0 & 0 & 0 \\
\hline Interstitial cell hyperplasia & - & - & - & - & 5 & 4 & 7 & 5 \\
\hline Interstitial cell tumor & - & - & - & - & 0 & 1 & 1 & 0 \\
\hline Mesothelioma & - & - & - & - & 0 & 0 & 1 & 0 \\
\hline Prostate & - & - & - & - & $(10)$ & $(10)$ & $(10)$ & $(10)$ \\
\hline Cellular infiltration, lymphocyte (1) & - & - & - & - & 0 & 0 & 1 & 0 \\
\hline Inflammation (1) & - & - & - & - & 0 & 0 & 0 & 1 \\
\hline Prostatic intraepithelial neoplasia & - & - & - & - & 1 & 0 & 0 & 0 \\
\hline Adenoma & - & - & - & - & 0 & 0 & 1 & 0 \\
\hline Epididymis & - & - & - & - & (10) & $(10)$ & $(10)$ & $(10)$ \\
\hline Atrophy (1) & - & - & - & - & 1 & 0 & 1 & 0 \\
\hline Mesothelioma & - & - & - & - & 0 & 0 & 1 & 0 \\
\hline Mammary gland & (10) & (10) & (10) & $(10)$ & (10) & (10) & $(10)$ & $(10)$ \\
\hline Hyperplasia & 0 & 3 & 0 & 0 & 0 & 3 & $4^{*}$ & 2 \\
\hline Uterus & (10) & (10) & (10) & $(10)$ & - & - & - & - \\
\hline Dilatation (1) & 0 & 1 & 3 & 3 & - & - & - & - \\
\hline Endometrial stromal polyp & 1 & 0 & 1 & 1 & - & - & - & - \\
\hline Eyes & (10) & (9) & (10) & (9) & (10) & (10) & $(10)$ & $(10)$ \\
\hline Not present & 0 & 1 & 0 & 1 & 0 & 0 & 0 & 0 \\
\hline Cataract (1) & 0 & 0 & 0 & 1 & 0 & 2 & 0 & 0 \\
\hline (3) & 0 & 0 & 1 & 0 & 0 & 0 & 0 & 0 \\
\hline Atrophy of retina (3) & 0 & 0 & 1 & 0 & 0 & 1 & 0 & 0 \\
\hline Brain & (10) & (10) & (10) & $(10)$ & (10) & (10) & $(10)$ & $(10)$ \\
\hline Astrocytoma & 0 & 0 & 0 & 1 & 0 & 0 & 0 & 0 \\
\hline
\end{tabular}

Grade : (1) slight (2) moderate (3) marked.

Numbers of rats examined are indicated in parentheses.

* : Significantly different from control group at $\mathrm{p}<0.05$.

Table 5. Hemosiderin deposition in the spleen of F344 rats treated with Hinokitiol in chronic study.

\begin{tabular}{lccc}
\hline \multirow{2}{*}{ Sex } & Dose $(\%)$ & No. of rats examined & Berlin blue staining \\
\hline Female & 0 & 5 & Area $\left(\mathrm{cm}^{2} / \mathrm{cm}^{2}\right)$ \\
& 0.005 & 5 & $0.42 \pm 0.08$ \\
& 0.015 & 5 & $0.32 \pm 0.10$ \\
& 0.05 & 5 & $0.36 \pm 0.16$ \\
& & & $0.43 \pm 0.04$ \\
Male & 0 & 5 & $0.15 \pm 0.09$ \\
& 0.005 & 5 & $0.22 \pm 0.03$ \\
& 0.015 & 5 & $0.21 \pm 0.04$ \\
& 0.05 & 5 & $0.36 \pm 0.03^{* *}$ \\
\hline
\end{tabular}

Values are Mean \pm SD values.

** : Significantly different from control group at $\mathrm{p}<0.01$. 
Chronic toxicity/carcinogenicity of hinokitiol.

plasia was significantly elevated in the mammary glands of male rats receiving $0.015 \%$ hinokitiol. Although the relative weights of male lungs and testes as well as female kidneys were significantly elevated in the rats that received $0.05 \%$ hinokitiol diet, no treatment-related histopathological changes were observed. No significant findings were observed in any other organs/tissues.

\section{Two-year carcinogenicity}

No treatment-related changes of physical appearance or general behavior were observed in any of the rats throughout the study. At the end of the study, the survival rates of females receiving $0,0.015$ and $0.05 \%$ hinokitiol were 86,86 and $82 \%$ respectively, and those of males receiving $0,0.005,0.015$ and $0.05 \%$ hinokitiol were 68, 90, 90 and $76 \%$, respectively. Significantly higher survival of the 0.005 and $0.015 \%$ male groups was noted as compared with the control group at the 104-week time point.

Body weight curves are illustrated in Fig. 2. Significant elevation was observed in the $0.015 \%$ female group as compared with the control group from weeks 48 to 104 . Also in the $0.05 \%$ female group, significant elevation of body weights was observed from weeks 98 to 104 . Body weight changes in the males were comparable in the control and hinokitiol groups.

Food consumption was similar in both control and treated groups (data not shown). The average intakes of hinokitiol were 7.8 and $25.9 \mathrm{mg} / \mathrm{kg}$ body weight/day for the $0.015 \%$ and $0.05 \%$ female groups and $2.1,6.4$ and $20.9 \mathrm{mg} / \mathrm{kg}$ body weight/day for the $0.005 \%, 0.015 \%$ and $0.05 \%$ male groups, respectively.

Hematological examinations did not reveal any marked changes related to hinokitiol treatment (data not shown).

No grossly visible changes related to hinokitiol treatment were found in either sex (data not shown). Furthermore, no organ weight changes related to hinokitol treatment were shown in either sex (data not shown).

Incidences of tumors are given in Table 6. The incidence of $\mathrm{C}$-cell adenomas in the thyroid of male rats receiving $0.05 \%$ hinokitiol was significantly

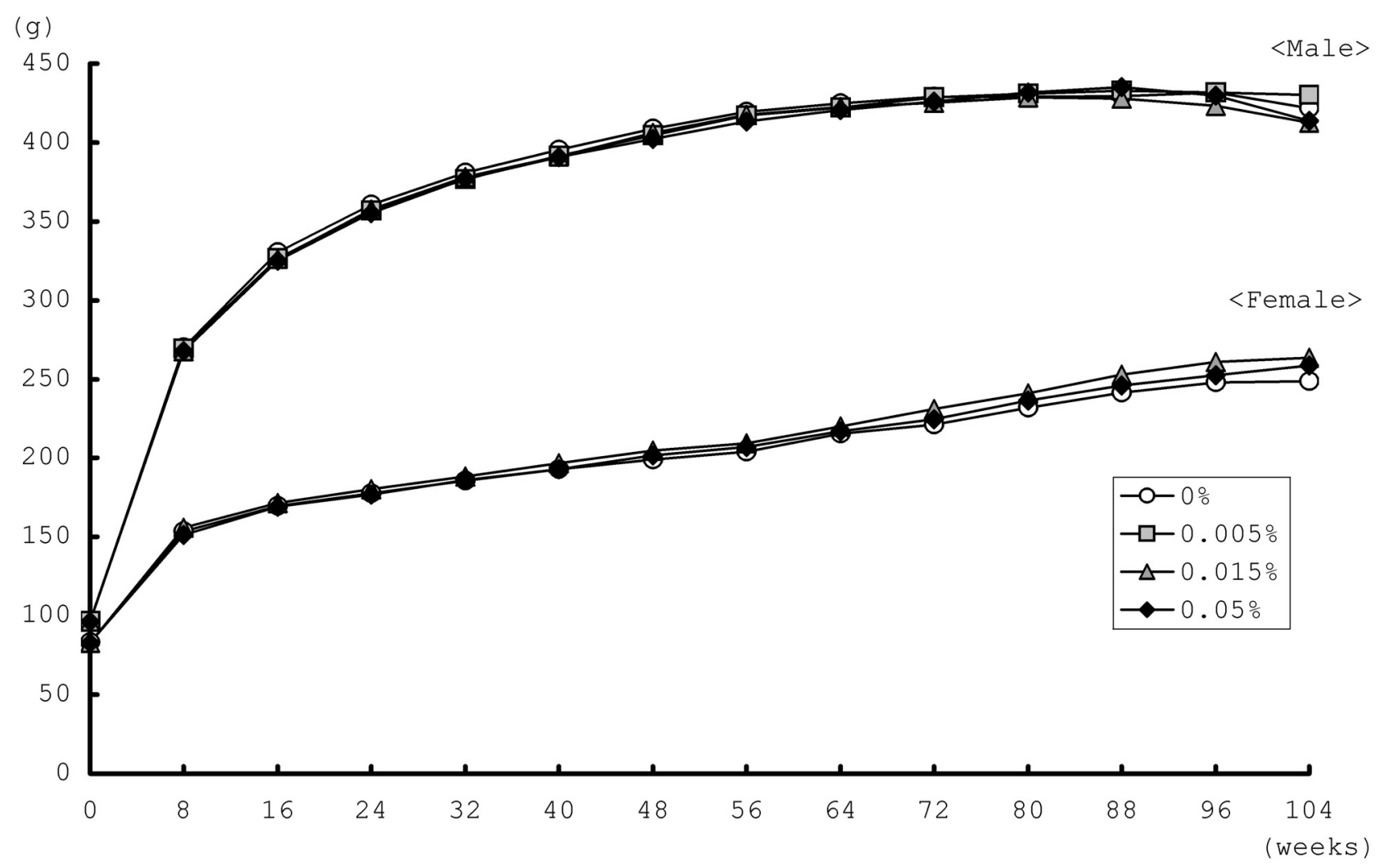

Fig. 2. Body weight changes in F344 rats treated with hinokitiol for 104 weeks. 
N. IMAI et al.

Table 6. Incidences of tumors in F344 rats treated with Hinokitiol in carcinogenic study.

\begin{tabular}{|c|c|c|c|c|c|c|c|}
\hline \multirow{3}{*}{ Site and type of tumors } & \multicolumn{7}{|c|}{ No. of rats with tumors } \\
\hline & \multicolumn{3}{|c|}{ Female } & \multicolumn{4}{|c|}{ Male } \\
\hline & 0 & 0.015 & 0.05 & 0 & 0.005 & 0.015 & 0.05 \\
\hline All sites & $(50)$ & $(50)$ & $(50)$ & $(50)$ & $(50)$ & $(50)$ & $(50)$ \\
\hline Malignant lymphoma/leukemia & 7 & 8 & 5 & 6 & 1 & 6 & 7 \\
\hline Heart & $(50)$ & $(50)$ & $(50)$ & $(50)$ & $(50)$ & $(50)$ & $(50)$ \\
\hline Schwannoma & 1 & 1 & 0 & 0 & 1 & 1 & 0 \\
\hline Spleen & $(50)$ & $(50)$ & $(50)$ & $(50)$ & $(50)$ & (49) & $(50)$ \\
\hline Sarcoma, NOS & 0 & 0 & 0 & 0 & 0 & 0 & 1 \\
\hline Bone marrow & $(50)$ & $(50)$ & $(50)$ & $(50)$ & $(50)$ & (50) & $(50)$ \\
\hline Histiocytic sarcoma & 0 & 0 & 0 & 0 & 0 & 0 & 1 \\
\hline Sarcoma, NOS & 0 & 0 & 0 & 0 & 0 & 0 & 1 \\
\hline Thymus & (49) & (47) & $(50)$ & (48) & $(50)$ & (50) & $(50)$ \\
\hline Thymoma & 1 & 0 & 0 & 0 & 0 & 1 & 1 \\
\hline Pituitary & $(50)$ & $(50)$ & $(50)$ & $(50)$ & $(50)$ & (49) & $(50)$ \\
\hline Adenoma, pars distalis & 17 & 22 & 21 & 10 & 10 & 7 & 4 \\
\hline Carcinoma, pars distalis & 0 & 0 & 2 & 1 & 1 & 1 & 0 \\
\hline Thyroids & $(50)$ & $(50)$ & $(50)$ & $(50)$ & $(50)$ & (50) & $(50)$ \\
\hline Follicular adenoma & 0 & 0 & 1 & 0 & 0 & 1 & 1 \\
\hline C-cell adenoma & 3 & 9 & 9 & 17 & 11 & 9 & $7 *$ \\
\hline Follicular carcinoma & 0 & 0 & 0 & 0 & 1 & 1 & 1 \\
\hline C-cell carcionoma & 2 & 0 & 0 & 2 & 0 & 3 & 0 \\
\hline Parathyroids & (49) & $(50)$ & $(50)$ & $(49)$ & $(50)$ & $(50)$ & $(50)$ \\
\hline Adenoma & 0 & 0 & 0 & 2 & 0 & 0 & 0 \\
\hline Adrenals & $(50)$ & $(50)$ & $(50)$ & $(50)$ & $(50)$ & $(50)$ & $(50)$ \\
\hline Pheochromocytoma & 0 & 0 & 0 & 4 & 1 & 3 & 10 \\
\hline Malignant pheochromocytoma & 0 & 0 & 0 & 0 & 0 & 2 & 1 \\
\hline Lungs & $(50)$ & $(50)$ & $(50)$ & $(50)$ & $(50)$ & $(50)$ & $(50)$ \\
\hline Adenoma & 0 & 1 & 0 & 2 & 2 & 2 & 0 \\
\hline Adenocarcinoma & 0 & 0 & 0 & 1 & 0 & 1 & 0 \\
\hline Salivary glands & $(50)$ & $(50)$ & $(50)$ & $(50)$ & $(50)$ & $(50)$ & $(48)$ \\
\hline Schwannoma & 0 & 0 & 0 & 0 & 0 & 0 & 1 \\
\hline Stomach & $(50)$ & $(50)$ & $(50)$ & $(50)$ & $(50)$ & (50) & $(50)$ \\
\hline Squamous cell papilloma & 1 & 0 & 0 & 0 & 1 & 0 & 0 \\
\hline Colon & $(50)$ & $(50)$ & $(50)$ & $(50)$ & $(50)$ & (50) & $(50)$ \\
\hline Adenocarcinoma & 0 & 1 & 0 & 0 & 0 & 0 & 0 \\
\hline Pancreas & $(50)$ & $(50)$ & $(50)$ & $(50)$ & $(50)$ & (50) & $(50)$ \\
\hline Islet-cell adenoma & 1 & 1 & 0 & 4 & 0 & 2 & 2 \\
\hline Acinar cell adenoma & 0 & 0 & 0 & 0 & 0 & 0 & 1 \\
\hline Islet-cell carcinoma & 0 & 0 & 0 & 0 & 1 & 0 & 0 \\
\hline Liver & $(50)$ & $(50)$ & $(50)$ & $(50)$ & $(50)$ & $(50)$ & $(50)$ \\
\hline Hepatocellular adenoma & 1 & 0 & 1 & 1 & 2 & 2 & 1 \\
\hline Hepatocellular carcinoma & 1 & 0 & 0 & 0 & 1 & 1 & 2 \\
\hline Kidneys & $(50)$ & $(50)$ & $(50)$ & $(50)$ & $(50)$ & $(50)$ & $(50)$ \\
\hline Adenocarcinoma & 1 & 0 & 0 & 0 & 0 & 0 & 0 \\
\hline Angiomyolipoma & 0 & 0 & 0 & 0 & 0 & 0 & 1 \\
\hline Hemangioma & 0 & 0 & 0 & 0 & 0 & 0 & 1 \\
\hline Urinary bladder & $(50)$ & $(50)$ & $(50)$ & $(50)$ & $(50)$ & $(50)$ & $(49)$ \\
\hline Transitional cell carcinoma & 2 & 0 & 0 & 0 & 0 & 1 & 1 \\
\hline Testes & - & - & - & $(50)$ & $(50)$ & $(50)$ & $(50)$ \\
\hline Interstitial cell tumor & - & - & - & 43 & 48 & 46 & 48 \\
\hline Prostate & - & - & - & $(50)$ & $(50)$ & $(50)$ & $(50)$ \\
\hline Carcinoma & - & - & - & 2 & 1 & 3 & 1 \\
\hline
\end{tabular}

Numbers of rats examined are indicated in parentheses.

* : Significantly different from control group at $\mathrm{p}<0.05$. 
Chronic toxicity/carcinogenicity of hinokitiol.

Table 6. Continued.

\begin{tabular}{|c|c|c|c|c|c|c|c|}
\hline \multirow{3}{*}{$\begin{array}{l}\text { Site and type of tumors } \\
\text { Dietary level (\%) --- } \\
\end{array}$} & \multicolumn{7}{|c|}{ No. of rats with tumors } \\
\hline & \multicolumn{3}{|c|}{ Female } & \multicolumn{4}{|c|}{ Male } \\
\hline & 0 & 0.015 & 0.05 & 0 & 0.005 & 0.015 & 0.05 \\
\hline Prep./clit. glands & (2) & (1) & (1) & (3) & $(0)$ & (2) & (3) \\
\hline Adenoma & 0 & 0 & 0 & 0 & 0 & 2 & 0 \\
\hline Carcinoma & 2 & 1 & 1 & 2 & 0 & 0 & 2 \\
\hline Mammary gland & $(50)$ & (49) & $(50)$ & $(50)$ & $(49)$ & (49) & $(50)$ \\
\hline Adenoma & 0 & 1 & 2 & 1 & 0 & 0 & 0 \\
\hline Fibroadenoma & 2 & 5 & 9 & 1 & 1 & 0 & 1 \\
\hline Adenocarcinoma & 1 & 0 & 1 & 1 & 0 & 1 & 0 \\
\hline Ovaries/oviduct & $(50)$ & $(50)$ & $(50)$ & - & - & - & - \\
\hline Sertori cell tumor & 1 & 0 & 0 & - & - & - & - \\
\hline Uterus & $(50)$ & $(50)$ & $(50)$ & - & - & - & - \\
\hline Endometrial adenoma & 1 & 0 & 0 & - & - & - & - \\
\hline Endometrial stromal polyp & 11 & 9 & 13 & - & - & - & - \\
\hline Leiomyoma & 0 & 1 & 0 & - & - & - & - \\
\hline Endometrial stromal sarcoma & 0 & 1 & 0 & - & - & - & - \\
\hline Malignant schwannoma & 0 & 1 & 1 & - & - & - & - \\
\hline Sarcoma, NOS & 0 & 0 & 1 & - & - & - & - \\
\hline Skin/subcutis & $(50)$ & $(50)$ & $(50)$ & $(50)$ & $(50)$ & $(50)$ & $(50)$ \\
\hline Squamous cell papilloma & 0 & 1 & 0 & 3 & 2 & 1 & 0 \\
\hline Keratoacanthoma & 0 & 0 & 0 & 3 & 3 & 1 & 2 \\
\hline Fibroma & 2 & 0 & 0 & 6 & 9 & 5 & 6 \\
\hline Lipoma & 0 & 0 & 0 & 0 & 0 & 0 & 1 \\
\hline Schwannoma & 0 & 0 & 0 & 1 & 3 & 0 & 1 \\
\hline Squamous cell carcinoma & 0 & 0 & 0 & 0 & 0 & 0 & 1 \\
\hline Basal cell carcinoma & 0 & 0 & 0 & 0 & 1 & 0 & 0 \\
\hline Fibrosarcoma & 0 & 1 & 0 & 1 & 0 & 2 & 1 \\
\hline Unclassified sarcoma & 0 & 1 & 0 & 0 & 0 & 0 & 0 \\
\hline Zymbal's glands & $(46)$ & (48) & $(48)$ & $(47)$ & $(47)$ & $(47)$ & $(49)$ \\
\hline Adenoma & 1 & 0 & 0 & 0 & 0 & 0 & 0 \\
\hline Eyes & $(50)$ & $(50)$ & $(50)$ & $(50)$ & $(50)$ & $(50)$ & $(50)$ \\
\hline Fibroma, eyelid & 1 & 0 & 0 & 0 & 0 & 0 & 0 \\
\hline Harderian glands & $(50)$ & $(50)$ & $(50)$ & $(50)$ & $(50)$ & $(50)$ & $(50)$ \\
\hline Adenoma & 0 & 1 & 0 & 0 & 0 & 0 & 0 \\
\hline Brain & $(50)$ & $(50)$ & $(50)$ & $(50)$ & $(50)$ & $(50)$ & $(50)$ \\
\hline Astrocytoma & 0 & 0 & 1 & 1 & 0 & 0 & 1 \\
\hline Meningial sarcoma & 0 & 0 & 0 & 1 & 0 & 0 & 0 \\
\hline Abdominal cavity & (0) & $(0)$ & $(0)$ & (6) & (3) & (5) & (4) \\
\hline Hemangiosarcoma & 0 & 0 & 0 & 0 & 0 & 1 & 0 \\
\hline Mesothelioma & 0 & 0 & 0 & 4 & 0 & 0 & 1 \\
\hline Others & (1) & (1) & $(0)$ & (4) & (9) & (4) & (4) \\
\hline Neural crest neoplasm, pinna & 1 & 0 & 0 & 0 & 0 & 0 & 0 \\
\hline Fibroma, costa & 0 & 1 & 0 & 0 & 0 & 0 & 0 \\
\hline Chordoma, vertebra & 0 & 0 & 0 & 1 & 0 & 0 & 1 \\
\hline Osteoma, vertebra & 0 & 0 & 0 & 0 & 1 & 0 & 0 \\
\hline Osteosarcoma, costa & 0 & 0 & 0 & 0 & 0 & 1 & 0 \\
\hline
\end{tabular}

Numbers of rats examined are indicated in parentheses. 
decreased as compared with the control group value. Incidences of benign or malignant tumors were otherwise comparable between the treated groups and controls of either sex.

As non-neoplastic lesions, a slight increase in hemosiderin deposits was significant in the spleens of male rats receiving $0.05 \%$ hinokitiol. Myocarditis observed in the 13-week subchronic toxicity study was found in only one out of fifty male rats given a diet containing $0.05 \%$ of hinokitiol. No treatment-related differences in other findings were observed in either sex (data not shown).

\section{DISCUSSION}

The present investigation of chronic toxicity and carcinogenicity of hinokitiol in female and male F344 rats fed the diet containing $0,0.005,0.015$ and $0.05 \%$ hinokitiol (excluding $0.005 \%$ females in the two-year carcinogenicity) for 52 or 104 weeks revealed no treated-related changes regarding clinical signs, survival rate, body weights and food consumption. Although some parameters of urinalysis, hematology and biochemistry demonstrated alterations these were not considered to be toxicologically adverse effects because of no dose-related alterations. Regarding slight but significant elevation of the spleen and liver weights, increased hemosiderin deposition in the spleen was noted in male rats receiving $0.05 \%$ hinokitiol, but not in females, as described below. It is unclear whether hemosiderin deposition contributed to the slight increase in spleen weights because of the lack in females. Hemosiderin in the spleen is generally increased with erythrocyte decomposition induced by toxicity and hemolytic anemia dependent on immunity. However, in the present experiments, no toxicologically adverse effects were apparent on hematology. Hinokitiol is known to be an iron chelator (Tanaka et $a l ., 1995)$, and this would explain the augmented hemosiderin deposits in the spleen. Another iron chelator, 8-hydroxyquinoline, has been reported to induce hemosiderosis in various organs, including the spleen and liver of Fischer strain rats when administered for 18 months, but this regimen was not found to be carcinogenic (Yamamoto et al., 1971). Although hemosiderosis was closely related to hinokitiol treatment, it was negligible and not toxicologically significant because no evidence of change was found in the hematology and histopathology. Furthermore, in the liver, it is also unclear whether centrilobular hypertrophy in male rats receiving $0.05 \%$ hinokitiol contributed to the slight increase in liver weight since the change was very slight.

The incidence of slight centrilobular hypertrophy of hepatocytes was significantly increased in the livers of male rats receiving $0.05 \%$ hinokitiol, but again this was not the case in females. While drug-metabolizing enzyme inducers are well documented to cause hypertrophy of centrilobular hepatocytes, hinokitiol is not reported to induce drug-metabolizing enzymes. Whatever the reason, there appeared to be no toxicological significance, given the low incidence and limited extent and lack of toxicity in the biochemistry and histopathological findings from the one-year chronic toxicity, and no proliferative alterations in the liver with the two-year carcinogenicity study. Furthermore, the elevated incidence of hyperplasia in the mammary glands of male rats receiving $0.015 \%$ hinokitiol can be considered incidental and not related to the treatment because of the lack of dose-relationship and no tumor induction in the carcinogenicity study.

In the 13-week subchronic toxicity study for dose-finding of hinokitiol, myocarditis was induced by hinokitiol treatment associated with dilatation of ventricles and large amounts of pleural fluid in male rats given diets containing $0.05,0.1$ and $0.2 \%$ of hinokitiol, but females were not affected. The order for severity of myocarditis was $0.1,0.2$ and $0.05 \%$, without clear dose-dependence. The alteration, which was characterized by focal loss of myofibers, fibrosis with inflammatory cells and coagulative necrosis, resembled severe spontaneous cardiomyopathy. Hypersensitivity myocarditis has been reported with several drugs, including local anesthestics and antibiotics (Artus et al., 1987; Buckley and Sanders, 2000; Hoehns et al., 2001; Kounis et al., 1989; Moons et al., 2001; Myers, et al., 1983; Van Vleet et al., 1991; Zaacks et al., 1999). However, in the present one-year and two-year studies, no myocarditis was found, and only one male rat out of fifty given the $0.05 \%$ hinokitiol developing lesions. The reason for variation in findings is unclear.

In our two-year carcinogenicity study, the incidence of C-cell adenoma in males of the $0.05 \%$ group (14\%) was significantly decreased as compared with the control group (34\%). However, in carcinogenic bioassays performed by the National Toxicology Program using F344 rats, the incidences of C-cell adenomas ranged from $0 \%$ to $34 \%$ (Haseman et al., 1990), so that the incidences actually observed in the present study can be considered to be within expectation for spontaneous development. Detailed histopathological examination revealed no treatment-related increase in 
Chronic toxicity/carcinogenicity of hinokitiol.

the incidences of any neoplastic lesions, given the lack of dose-response relationship and the fact that all data were within historical control ranges.

In conclusion, the present investigation demonstrated no carcinogenic potential in either sex of F344 rats fed hinokitiol (up to $0.05 \%$ dietary level) for 104 weeks.

\section{ACKNOWLEDGMENT}

This study was supported by the Ministry of Health, Labour and Welfare of Japan, and the Society for Promotion of Pathology of Nagoya, Japan.

\section{REFERENCES}

Artus, J.A., Cockburn, A., Fuller, J., McMurdo, A.S. and White, D.J. (1987): The preclinical toxicology of anisoylated plasminogen streptokinase activator complex. Drugs, 33 (suppl. 3), 97-101.

Buckley, N.A. and Sanders, P. (2000): Cardiovascular adverse effects of antipsychotic drugs. Internatl. J. med. toxicol. Drug experience, 23, 215-228.

Dunnett, C.W. (1955): A multiple procedure for comparing several treatments with a control. J. Am. Stat. Assoc., 50, 1096-1121.

Ema, M., Harazono, A., Fujii, S. and Kawashima, K. (2004): Evaluation of developmental toxicity of beta-thujaplicin (hinokitiol) following oral administration during organogenesis in rats. Food Chem. Toxicol., 42, 465-470.

Fisher, R.A. (1955): Statistical methods and scientific induction. J. R. Stat. Soc. [B], 17, 69-78.

Gad, S.C. and Weil, C.S. (1989): Statistics for toxicologists. In Principles and methods of toxicology (Hayes, A.W., ed.), pp. 435-483. Raven Press, Ltd., New York, NY.

Haseman, J.K., Arnold, J. and Eustis, S.L. (1990): Tumor incidences in Fischer 344 rats: NTP historical data. In Pathology of the Fischer Rat, (Boorman, G.A., Eustis, S.L., Elwell, M.R., Montogomery, C.A. Jr. and Mackenzie, W.F., eds.), pp. 555-564. Academic Press, Inc., San Diego, CA.

Hoehns, J.D., Fouts, M.M., Kelly, M.W. and Tu, K.B. (2001): Sudden cardiac death with clozapine and sertraline. Ann. Pharmacother., 35, 862866.

Ido, Y., Muto, N., Inada, A., Kohroki, J., MaZno, M., Odani, T., Itoh, N., Yamamoto, K. and Tanaka, K. (1999): Induction of apoptosis by hinokitiol, a potent iron chelator, in teratocarcinoma $\mathrm{F} 9$ cells is mediated through the activation of caspase-3. Cell Prolif., 32, 63-73.

Kounis, N.G., Zavras, G.M., Soufras, G.D. and Kitrous, M.P. (1989): Hypersensitivity myocarditis. Ann. Allergy, 62, 71-74.

Moons, L., Vanlinthout, I., Roelants, I., Moreadith, R., Collen, D. and Rapold, H.J. (2001): Toxicology studies with recombinant staphylokinase and with SY 161-P5, a polyethylene glycol-derivatized cysteine-substitution mutant. Toxicol. Pathol., 29, 285-291.

Myers, D.F., O'Connell, J.B. and Subramanian, R. (1983): Myocarditis resolving after discontinuation of procainamide. Internatl. J. Cardiol., 4, 322-324.

Nakagawa, Y. and Tayama, K. (1998): Mechanism of mitochondrial dysfunction and cytotoxicity induced by troplones in isolated rat hepatocytes. Chem.-Biol. Interact., 116, 45-60.

Nakano, S. (1959): Experimental and clinical studies on unsaturated seven-membered ring compounds. $34^{\text {th }}$ Report. The effect of Hinokitiolnatrium and tropolone upon organs of mice through long-term oral administration. Nigata Igaku-kai Zasshi, 73 (suppl. 1), 119-125 (in Japanese).

Ogata, A., Ando, H., Kubo, Y., Nagasawa, A., Ogawa, H., Yasuda, K. and Aoki, N. (1999): Teratogenicity of thujaplicin in ICR mice. Food Chem. Toxicol., 37, 1097-1104.

Shimizu, M., Noda, T., Yamano, T., Yamada, A. and Morita, S. (1993): Acute oral toxicity of natural food additives in mice and rats. Seikatsu Eisei, 37, 215-220 (in Japanese).

Tanaka, T., Muto, N., Itoh, N., Dota, A., Nishina, Y., Inada, A. and Tanaka, K. (1995): Induction of differentiation of embryonal carcinoma F9 cells by iron chelators. Res. Commun. Mol. Pathol. Pharmacol., 90, 211-220.

Tanaka, T., Muto, N., Ido, Y., Itoh, N. and Tanaka, K. (1997): Induction of embryonal carcinoma cell differentiation by deferoxamine, a potent therapeutic iron chelator. Biochim. Biophys. Acta, 1357, 91-97.

Tanaka, T., Satoh, T., Onozawa, Y., Kohroki, J., Itoh, N., Ishidate, M.Jr., Muto, N. and Tanaka, K. (1999): Apoptosis during iron chelator-induced differentiation in F9 embryonal carcinoma cells. Cell Biol. Int., 23, 541-550.

Ueno, S. and Ishizaki, M. (1992): The DNA-damaging 
activity of natural food additives (VI). Syokuhin Eiseigaku Zasshi, 33, 378-382 (in Japanese).

Van Vleet, J.F., Ferrana, V.J. and Herman, E. (1991):

Cardiovascular and skeletal muscle systems. In

(Haschek, W.M. and Rousseaux, C.G., eds.), Handbook of toxicologic pathology, pp. 539624 Academic Press, Inc.

Yamamoto, R.S., Williams, G.M., Frankel, H.H. and
Weisburger, J.H. (1971): 8-Hydroxyquinoline: Chronic Toxicity and inhibitory effect on the carcinogenicity of $N$-2-fluorenylacetamide. Toxicol Appl. Pharm., 19, 687-698.

Zaacks, S.M., Klein, L., Tan, C.D., Rodriguez, E.R. and Leikin, J.B. (1999): Hypersensitivity myocarditis associated with ephedra use. J. Toxicol.Clin. Toxicol., 37, 485-489. 